18. Кадина И.В. Игровые методы обучения в системе профессиональной подготовки специалистов агроинженерного профиля: дис. ... канд. пед. наук. Волгоград, 2008. 189 с.

19. Соловова Е.Н. Методика обучения иностранным языкам. Продвинутый курс // Пособие для сту- дентов педагогических вузов и учителей. 2-е изд. М.: Просвещение, 2010. 270 с.

20. Гальскова Н.Д., Дёмина М.Г., Манукян К.М. Цель обучения иностранным языкам в новейший период развития методики как науки // Иностранные языки в школе. 2012. № 5. С. 2-11.

\title{
COMMUNICATIVE COMPETENCY AS ABILITY AND READINESS OF THE CADETS TO FOREIGN CONVERSATION
}

(C) 2017

\author{
Girenok Galina Anatolievna, candidate of pedagogical sciences, \\ associate professor of Philosophy and Humanities Department \\ Samara Law Institute of the Federal Penitentiary Service of Russia (Samara, Russian Federation)
}

Abstract. This paper is devoted to the question of the development of the communicative competency at the English lessons in the departmental institutes of the FPS of Russia. At present much attention in education is paid to competencies development process that goes to show the effectiveness of the competency-based approach in this country. Under this approach the priority is given to the new style professionals' training. Such professionals are able to cope with all professional problems quickly and in a proper way using all their knowledge, abilities, skills and experience. This approach is a basis for totally new education which provides the improvement of occupation mobility and adaptability of our graduates. It brings them an opportunity to be at the forefront of the latest developments and innovation and foresee all possibilities of the situation. In the paper the definition of the communicative competency is revealed as ability and readiness of the cadets to foreign conversation. Much emphasis is made to the fact that both formation of the internal readiness and ability to foreign conversation may be the basis for successful communicative competency development.

Keywords: competency-based approach; Federal State Educational Standards of Higher Education; communicative competency development; occupation mobility; ability and readiness; foreign conversation; effectiveness of educational process; cadets of departmental institute.

УДК $37+17.02$

Статья поступила в редакцию 01.06.2017

\section{К ВОПРОСУ О НРАВСТВЕННОСТИ КАК СВОЙСТВЕ ЧЕЛОВЕКА: ПЕДАГОГИЧЕСКИЙ АСПЕКТ}

(C) 2017

Гущина Анна Владимировна, кандидат педагогических наук, доцент, проректор по учебной и воспитательной работе

Мурманский арктический государственный университет (2. Мурманск, Российская Федерация)

Аннотация. В данной статье обосновывается значение воспитания нравственности будущего учителя; показывается, что решение данной задачи, связанное с приобщением студента к находящимся в основаниях норм морали ценностям, удовлетворяет потребность нашего общества в нравственном учителе; приводятся доказательства, что нравственный педагог призван воспитывать человека, способного жить среди людей; показывается, что нравственный человек чтит память предков, хранит в своей нравственной памяти памятные даты, поддерживает сохранившиеся и сохраняющиеся традиции; выявляются две точки зрения ученых относительно нравственности как свойства человека: согласно первой точке зрения, нравственность человека сводится к знанию им норм морали и к отношению к себе и к окружающей действительности в образовательном процессе (в структуре такого отношения, которое ограничивается образовательным процессом, отсутствует отношение человека к другим людям, к моральным нормам, оценочное отношение как ступень ценностного отношения, критерием которых являются ценности культуры и морали, а сами ценности как основания норм морали не определяют содержание нравственности человека); согласно второй точке зрения, нравственность как свойство человека проявляется в общественном бытии, а ее форма и внешнее проявление - социальны, ее функция - сохранение коллективных связей, а тем самым и общества.

Ключевые слова: воспитание; нравственность; ценность; учитель; нравственный человек; нравственный учитель; категория; значение; чувство стыда; культура; существо нравственное; существо общественное; правила морали; функция нравственности.

Воспитание нравственности будущего учителя это актуальная для современного общества и образования проблема. Ее решение, связанное с приобщением студента к находящимся в основаниях норм морали ценностям, вокруг которых консолидируются люди при решении многообразных проблем современности, удовлетворяет потребность нашего общества в нравственном учителе. Нравственный педагог способен не только противостоять аморализму, безнравственности, имморализму, но и развивать способность к такому противостояния у учащихся. Такой педагог четко осознает, что заявляющие о себе в мире идеи исключительности одного народа над другим, одних людей над другими, являясь предвозвестниками возрождения фашизма, нацизма, расчеловечивают человека. Нравственный 
Гущина А.B.

К вопросу о нравственности как свойстве человека: педагогический аспект

13.00.00 - педагогические науки

педагог призван воспитывать человека, способного жить среди людей, согласовывая свои интересы с интересами другого человека. На значение воспитания ребенка, прежде всего, как человека указывали многие мыслители и педагоги прошлого. Так, Ж.-Ж. Руссо пишет: «Жить - вот ремесло, которому я хочу учить его (моего воспитанника. - А.Г.). Выходя из моих рук, он не будет - соглашаюсь в этом - ни судьей, ни солдатом, ни священником: он будет прежде всего человеком; всем, чем должен быть человек, он сумеет быть, в случае надобности, так же хорошо, как и всякий другой, и, как бы судьба не перемещала его с места на место, он всегда будет на своем месте» [1, с. 30-31].

Любой действительно нравственный человек, ориентированный на достижение блага для себя и для другого, на своем месте способствует процветанию государства. Он чтит память предков, хранит в своей нравственной памяти памятные даты, поддерживает сохранившиеся и сохраняющиеся традиции, «опора на которые позволяет человеку противостоять разрушительным влияниям и продуктивно развивать свое сознание, жизнь, саму систему общественных отношений» [2, с. 18]. Нравственный человек способен осуществлять реальный выбор - «выбор между хорошей и плохой жизнью» [3, с. 32].

Среди многих проблем, возникающих при решении задачи воспитания нравственности будущего учителя, требуется выявить значения категории «нравственность». Говоря о необходимости выявления значений категории «нравственность», мы имеем в виду то, как нравственность человека понимается в науке: как свойство человека (Л.Н. Овинова [4], Э.А. Поздняков [5] и др.); как качество человека (С.В. Подзорова [6]); как социально-психологическое образование [7, с. 23], как явление (О.М. Петрашкевич-Тихомирова [8], Э.А. Поздняков [9] и др.).

В данной статье мы обращаемся к идеям ученых, осмысливающих нравственность как свойство человека. Анализируя идеи ученых о нравственности как свойстве человека, мы сохраняем их терминологию в том смысле, что они, размышляя о нравственности, употребляют термин «понятие» - понятие «нравственность». Мы, размышляя о нравственности, употребляем термин «категория» - категория «нравственность». «Согласно философской традиции, пишет М.Г. Ярошевский, - под категориями имеются в виду наиболее общие, предельные понятия (такие, например, как «количество», «качество», «форма», «содержание» и т.п.)» [10, с. 124]. Такими общими, предельными понятиями являются и понятия «мораль», «нравственность», употребляемые в статусе категорий. Категории «мораль» и «нравственность» «не выводятся из других и не сводятся к другим» $[10$, c. 125].

Заметим, что первостепенное значение для нас имеет не просто нравственность человека, но нравственность учителя, который, естественно, является человеком.

Обратимся вначале к идеям ученых-педагогов о нравственности.

Л.Н. Овинова, придерживаясь того подхода, который основывается на разграничении понятий «мораль» и «нравственность» и соотносит нравственность с личностью, предлагает следующее определе- ние понятия «нравственность»: «Нравственность это свойство человека, базирующееся на знаниях норм морали, которое проявляется в его отношениях к себе, к окружающей действительности в образовательном процессе и в других аспектах жизнедеятельности» [4, с. 19].

Прежде чем осмыслить данное определение нравственности, заметим, что ученый пишет, что нравственность, имеющая субъективный характер, есть личностная характеристика [4, с. 21]. Как свойство человека, нравственность развивается в образовательном процессе. Вопрос: «Нравственность - это свойство человека или его личностная характеристика?» Ответ на этот вопрос мы не находим в работе Л.Н. Овиновой.

Осмысление предлагаемого Л.Н. Овиновой определения понятия «нравственность» показывает, что нравственность человека, по сути, сводится к знанию им норм морали и к отношению к себе и к окружающей действительности в образовательном процессе. Отсутствует не просто отношение человека к другим людям, к моральным нормам, но оценочное отношение как ступень ценностного отношения. При этом отношение к окружающей действительности ограничивается образовательным процессом. Вне поля зрения ученого оказываются ценности культуры и морали, та действительность, которая не укладывается в рамки образовательного процесса. Это социальнонравственная действительность с ее противоречиями.

Учитывая роль образования в воспитании нравственности, Л.Н. Овинова рассматривает педагогические аспекты нравственности, которые ученый называет свойствами нравственности, являющимися объектами педагогического влияния. В качестве одного из аспектов нравственности или ее свойств ученый выделяет наполнение «определенных элементов содержания образования этическим знанием, для того чтобы повысить осведомленность учащихся в области морали» [4, с. 19].

Наполнение «определенных элементов содержания образования этическим знанием» не является объектом педагогического влияния. Объектом педагогического влияния является ученик, его деятельность, отношения, ценности и т.д. Заметим, что ученый не указывает, что это за элементы содержания образования. Если это концепция содержания образования, разработанная И.Я. Лернером [11] и дополненная В.В. Краевским [12], то речь должна в первую очередь идти о первом и четвертом элементах содержания образования, а именно: «уже добытые обществом знания о природе, обществе, мышлении, технике и способах деятельности» (первый элемент) и «система норм отношений к миру, к людям, друг к другу» (четвертый элемент). Если это разработанная на основе компетентностного подхода концепция содержания образования, то речь должна идти о практическом результате профессиональной подготовки в виде «знать», в содержании которого и должно находиться этическое знание. Если наполнение «определенных элементов содержания образования этическим знанием» не является объектом педагогического влияния, то не ясно, о каком свойстве нравственности идет речь. 
В качестве другого аспекта нравственности или ее свойства ученый выделяет «взаимодействие учащихся с субъектами образовательного процесса: преподавателями, сокурсниками, товарищами по группе» $[4$, с. 19].

Если вести речь о взаимодействии, то, с нашей точки зрения, необходимо не просто взаимодействие, а нравственно-педагогическое взаимодействие, что усилит позиции в деле воспитания нравственности студентов. Однако не ясно, почему взаимодействие учащихся с субъектами образования является педагогическим аспектом нравственности, или свойством нравственности. Взаимодействие - это не свойство нравственности, которая, по мысли Л.Н. Овиновой, сама является свойством человека.

Завершая осмысление предлагаемых Л.Н. Овиновой педагогических аспектов нравственности, отметим, что речь должна идти в лучшем случае о педагогических аспектах воспитания нравственности, а не о педагогических аспектах собственно нравственности или ее свойствах. В деле воспитания нравственности будущего учителя значение имеет и формирование этических знаний студента, и организация его взаимодействия с субъектами образования.

Обратимся к идеям культурологов. Э.А. Поздняков исследует нравственность, отвечая на такие поставленные вопросы: «Почему человек есть "существо нравственное"?», «Где лежат корни нравственности?» Прежде чем осмыслить идеи ученого о нравственности, заметим, что Э.А. Поздняков, если исходить из различий морали и нравственности по критерию «внешнее» и «внутреннее», употребляет термин «нравственность» то в значении морали как внешней по отношению к человеку, то в значении нравственности как «мир человека и человеческих отношений», то исходит из единства морали и нравственности.

Э.А. Поздняков, комментируя представленное в «Краткой философской энциклопедии» 1994 года (издательство «Прогресс») определение нравственности: «Нравственность заключается в добровольном самодеятельном согласии чувств, стремлений и действий членов общества с чувствами, стремлениями и действиями сограждан, их интересом и достоинством, с интересом и достоинством всего общества в целом. Добровольность и самодеятельность отличают всякое явление нравственности. Нравственное чувство является, по Канту, «некоторой ощущаемой зависимостью частной воли от общей»») [Цит. по: 9, c. 306], пишет, что по аналогии с И. Кантом следует признать, что всякое общественное существо ввиду своей зависимости от общей воли признается существом нравственным.

Заявив, что понятие нравственности не вытекает прямо и непосредственно из общественной организации живых существ, Э.А. Поздняков подчеркивает, что «суждение типа: «человек есть существо нравственное, потому что он существо общественное», не работает. Сама нравственность есть некоторое свойство человека, но свойство, которое проявляется только в общественном бытии» [9, с. 307].

Действительно, если человек живет среди людей, среди себе подобных, это еще не означает, что он по определению человек нравственный. Нравственным он становится в процессе воспитания и образования, в процессе взаимодействия с другими людьми, в процессе жизнедеятельности. Нравственность не врожденное, а приобретенное свойство.

Заметим, что в отличие от Л.Н. Овиновой, которая просто заявляет, что нравственность есть свойство человека, Э.А. Поздняков утверждает, что нравственность как свойство человека проявляется в общественном бытии. Однако и это утверждение, как пишет Э.А. Поздняков, не приближает нас к ответу на поставленные вопросы. Важно выявить признаки и критерии нравственности. Мы не приводим всех рассуждений и размышлений ученого о признаках и критериях нравственности, а приводим результаты таких размышлений и рассуждений. Первым признаком нравственности и ее же критерием, согласно Э.А. Позднякову, является чувство стыда [9, с. 308]. Однако и этого, по мысли ученого, недостаточно, чтобы понять до конца суть нравственности.

Э.А. Поздняков, приводя доказательства того, что чувство стыда определяет нравственность, как на индивидуальном, так и на общественном уровнях, что оно возникает только в среде других, перед другими, в обществе, каким бы малым оно ни было, что, захватывая другие области отношений, создает целостную систему нравственности, систему, строящуюся на понимании того, «что такое хорошо и что такое плохо», делает вывод: «Нравственность явление не случайное, оно выражает сущностную сторону человека, а тем самым и культуры. <...> Культура есть не что иное, как система нравственных норм, определяющая быт и поведение человека. Как таковая, она пронизывает все сферы индивидуальной и общественной жизни и деятельности, а потому не только отдельный индивид, но и общество в целом предстают как нравственные личности. <..> Нравственность есть не только фундамент культуры, но и сама культура» [9, с. 308].

Мы видим, что Э.А. Поздняков при обосновании сути нравственности, употребляет этот термин то в значении «внутреннего» - нравственность на индивидуальном уровне, то есть относящаяся к индивиду, то в значении «внешнего» - нравственность на общественном уровне, то есть относящаяся к обществу (общественная мораль. - А.Г.). Ученый рассуждает о нравственности, исходя из единства морали и нравственности. И мораль, и нравственность, если исходить из различения данных явлений по критерию «внешнее» и «внутреннее», пронизывают все сферы индивидуальной (нравственность. - А.Г.) и общественной (мораль. - А.Г.) жизни, деятельность отдельного человека (нравственность. - А.Г.) и деятельность совокупного субъекта (мораль. - А.Г.).

Для нас важным является указание ученого на то, что нравственность есть явление, которое выражает самою культуру. Мы полагаем, что нравственность есть явление культуры.

Утверждение Э.А. Позднякова о том, что «нравственность есть не только фундамент культуры, но и сама культура» - это сильное утверждение, означающее, что культура без нравственности человека это не совсем культура, как бы она не трактовалась. Для понимания сущности нравственности, как подчеркивает Э.А. Поздняков, и этого утверждения еще не достаточно. Ученый вновь обращается к положению о том, что человек есть существо общественное. 
Приведя доказательства того, что природа, сохранив человека как существо общественное, дала ему специальные средства, среди которых главным стала нравственность, «рассматриваемая как система общеобязательных для любого конкретного сообщества людей норм и правил поведения, которые оно само же сознательно и вырабатывает и с помощью которых оно способно сохранить себя как таковое и обеспечить продолжение рода. <..> Ее (нравственности. - А.Г.) форма и внешнее проявление - социальны, то есть присущи только сообществу существ, обладающих разумом-воображением» [9, с. 312 313], Э.А. Поздняков употребляет термин «нравственность» в значении «внешнего» - нормы и правила поведения, приходящие к человеку извне от имени общества.

Заметим, что человек сам может формулировать для себя правила поведения. Так, Р. Декарт составил себе правила морали или максимы. Это, «во-первых, повиноваться законам и обычаям моей страны, неотступно придерживаться религии, в которой <..> я был воспитан с детства, и руководствуясь во всем остальном наиболее умеренными и чуждыми крайностей мнениями, сообща выработанными самыми благоразумными людьми, в кругу которых мне предстояло жить. <..> Моим вторым правилом было оставаться настолько твердым и решительным в своих действиях, насколько это было в моих силах. <..> Моим третьим правилом было всегда стремиться побеждать скорее себя, чем судьбу (fortune), изменять свои желания, а не порядок мира и вообще привыкнуть к мысли, что в полной нашей власти находятся только наши мысли» [13, с. 263-264].

Сформулированные Р. Декартом правила морали сохраняют свое значение и для современного человека, заботой которого является забота о правильной, то есть нравственной жизни. Человек, соблюдая законы и обычаи своей страны, придерживаясь религии, в которой воспитан с детства, умеренных мнений, отвергает крайности, которые приводят не только к противоречиям между людьми, но и к конфликтам, не навязывает своей религии другим людям, не понуждает их жить в соответствии с навязываемыми извне ценностями. Стремясь изменить себя, он не стремится изменить миропорядок, являясь противником свержения неугодных режимов. Изменение режимов на Ближнем Востоке, в Африке привели к хаосу, к войне, к гибели мирных жителей, к невиданному переселению народов, к расползанию идей терроризма в Европе. Третье сформулированное Р. Декартом правило важно для современных политиков, для которых главными должны стать национальные интересы, нужды своего народа, а не навязывание своих ценностей, норм другим народам. Я видел, пишет Р. Декарт, «как многое из того, что представляется нам смешным и странным, оказывается общепринятым и одобряемым у других великих народов» [13, с. 255].

Современная школа должна создавать условия для того, чтобы обучающиеся воспитывали себя в правилах морали, в том числе и в сохранившихся и сохраняющихся, имеющих непреходящее значение для современности и сформулированных еще Р. Декартом правилах морали. Отметим, что мы уже осмысливали сформулированные Р. Декартом прави- ла морали или максимы при выявлении его идей о морали и нравственности в их приложении к воспитанию $[14$, с. 180]. В нашей статье, посвященной данной проблеме [14], мы, приводя сформулированные Р. Декартом правила морали, ориентируем педагогов на осмысление таких правил совместно с учащимися, а также на совместную с ними формулировку правил морали или максим.

Возвращаясь к идеям Э.А. Позднякова о нравственности, заметим, что ученый полагает, что истинной функцией нравственности является «сохранение коллективных связей, а тем самым и общества» $[9$, с. 314]. Говоря об истинной функции нравственности, ученый исходит из единства морали и нравственности. Наше утверждение основывается на том, что Э.А. Поздняков употребляет термин «нравственность» и в значении внешнего, то есть как мораль, и в значении внутреннего, то есть как нравственность. И мораль как внешнее по отношению к человеку на общественном уровне, и нравственность как внутреннее, характеризующая внутренний мир человека, на личностном уровне способствуют сохранению общественных, коллективных связей, а тем самым и общества.

Аналогичную точку зрения на мораль годом ранее Э.А. Позднякова высказывает А.А. Гусейнов. Задавшись вопросом: «Что останется в отношениях между ними (людьми. - А.Г.), если полностью вычесть из них «что-то», все конкретное, все те вещи, интересы, потребности, по поводу которых эти отношения строятся?», А.А. Гусейнов отвечает: «Останется то, что делает возможными эти отношения, их общественная форма, самая изначальная потребность людей в совместной жизни как естественном и единственно возможном условии их существования. Это и будет мораль» $[15$, с. 22]. Мораль предохраняет общество от разложения и следующего за ним распада.

Итак, анализ идей ученых о нравственности как свойстве человека выявил две точки зрения относительно такого понимания нравственности. Согласно первой точке зрения, нравственность человека сводится к знанию им норм морали и к отношению к себе и к окружающей действительности в образовательном процессе. В структуре такого отношения, которое ограничивается образовательным процессом, отсутствует отношение человека к другим людям, к моральным нормам, оценочное отношение как ступень ценностного отношения, критерием которых являются ценности культуры и морали, а сами ценности как основания норм морали не определяют содержание нравственности человека. Согласно второй точке зрения, нравственность как свойство человека проявляется в общественном бытии, а ее форма и внешнее проявление - социальны, ее функция - сохранение коллективных связей, а тем самым и общества.

\section{СПИСОК ЛИТЕРАТУРЫ:}

1. Руссо Ж.-Ж. Педагогические сочинения. В 2 т. Т. 1. М.: Педагогика, 1981. 656 с.

2. Данилюк А.Я., Кондаков А.М., Тишков В.А. Концепция духовно-нравственного развития и воспитания личности гражданина России. М.: Просвещение, 2009. 24 с. 
3. Фромм Э. Психоанализ и этика. М.: Республика, 1993. 416 с.

4. Овинова Л.Н. Нравственность как педагогическое понятие // Вестник Южно-Уральского государственного университета. 2006. № 16(71). Серия «Образование. Здравоохранение. Физическая культура». C. $18-21$.

5. Поздняков Э.А. Философия культуры. М.: Интурреклама, 1999. 576 с.

6. Подзорова С.В. К вопросу о сущности понятия «нравственность»// Современная наука. 2011. № 2. C. $51-55$.

7. Лихачев Б.Т. Философия воспитания. Специальный курс: учебное пособие для студентов высших учебных заведений. М.: Прометей, 1995. 282 с.

8. Петрашкевич-Тихомирова О.М. Культурология как теория культуры. М.: Академический Проект, 2005. 272 c.

9. Поздняков Э.А. Философия культуры. М.: Интурреклама, 1999. 576 с.

\section{MORALITY AS A PROPERTY OF HUMAN: \\ THE PEDAGOGICAL ASPECT}

(C) 2017
10. Ярошевский М.Г. Теоретическое и категориальное в системе науки // Основы теоретической психологии / А.В. Петровский, М.Г. Ярошевский. М.: ИНФРА-М, 1998. С. 123-138.

11. Лернер И.Я. Дидактические основы методов обучения. М.: Педагогика, 1981. 186 с.

12. Краевский В.В. Содержание образования: вперед к прошлому. М.: Педагогическое общество России, 2001. 36 с.

13. Декарт Р. Сочинения. В 2 т. Т. 1. М.: Мысль, $1989.654 \mathrm{c}$

14. Гущина А.В. Идеи Ф. Бэкона, Р. Декарта, Т. Гоббса о морали и нравственности в их приложении к воспитанию // Самарский научный вестник. 2017. Т. 6, № 1 (18). С. $178-182$.

15. Гусейнов А.А. Предмет этики // Этика: учебник / А.А. Гусейнов, Р.Г. Апресян. М.: Гардарики, 1998. C. 9-28.

Guschina Anna Vladimirovna, candidate of pedagogical sciences, associate professor, vice rector for academic and educational work Murmansk Arctic State University (Murmansk, Russian Federation)

\begin{abstract}
In this paper the author shows that it is important to teach morality to prospective teachers. The author also shows that the solution of this task connected with the introduction of the student to the values that are in the norms of morality satisfies the need of our society in the moral teacher. The paper contains evidence that a moral educator is called upon to educate a person who can live among people. The author shows that a moral person honors the memory of ancestors, keeps memorable dates in his moral memory, and supports the preserved and preserved traditions. Two points of view of scientists regarding morality as human properties are revealed: according to the first point of view, a person's morality comes down to knowing the norms of morality towards himself/herself as well as towards the surrounding reality in the educational process; according to the second point of view, morality as a property of man is manifested in social being, and its form and external manifestation are social, its function is the preservation of collective ties, and thus of society.

Keywords: upbringing; morality; value; teacher; moral person; moral teacher; category; meaning; sense of shame; culture; moral being; social being; moral rules; morality function.
\end{abstract}

УДК 378.147

Статья поступила в редакцию 08.06.2017

\title{
СТРУКТУРНО-ФУНКЦИОНАЛЬНАЯ МОДЕЛЬ ФОРМИРОВАНИЯ ПРОФЕССИОНАЛЬНОЙ КОМПЕТЕНТНОСТИ БУДУЩЕГО УЧИТЕЛЯ МАТЕМАТИКИ
} (C) 2017

Зверева Екатерина Яковлевна, старший преподаватель кафедры информатики, теории и методики обучения информатике Забайкальский государственньй университет (г. Чита, Российская Федерация)

Аннотация. В данной статье рассматривается структурно-функциональная модель формирования профессиональной компетентности будущего учителя математики посредством контекстных задач по математическому анализу при реализации компетентностного и контекстного подходов при обучении студентов по направлению подготовки «Педагогическое образование». Проведен анализ научной и методической литературы по компетентностному подходу и основного понятия данной статьи «Модель». В исследовании определены основные компоненты процесса формирования профессиональной компетентности будущего учителя математики: информационно-методологическая, предметно-методическая, социально-коммуникативная, личностно-валеологическая компетенции, формирование и развитие которых происходит в процессе решения контекстных задач по математическому анализу, которые подразделяются на предметные, межпредметные, практические и профессиональные. Описывается единство структурных (цель, методология, содержание и организация процесса, результат) и функциональных компонентов модели (этапы, критерии, показатели, уровни сформированности профессиональной компетентности будущего учителя математики). В каждом структурном компоненте модели подробно описано содержание и определяющие моменты. Сделан вывод, что разработанная модель формирования профессиональной компетентности будущего учителя математики может быть использована для формирования профессиональной компетентности будущего учителя другого 